\title{
Superconductivity in the Endohedral Ga Cluster Compound $\mathrm{PdGa}_{5}$
}

\section{Supplementary Material}

Zuzanna Ryżyńska ${ }^{\dagger}$, Piotr Wiśniewski ${ }^{\ddagger}$, Dariusz Kaczorowski ${ }^{\ddagger}$, Weiwei Xie ${ }^{\#}$, Robert J. Cava ${ }^{\Uparrow}$, Tomasz Klimczuk $^{\dagger}$, Michał J. Winiarski ${ }^{\dagger}{ }^{\dagger}$

${ }^{\dagger}$ Faculty of Applied Physics and Mathematics and Advanced Materials Center, Gdansk University of Technology, Narutowicza 11/12, 8o-232 Gdansk, Poland

${ }^{\ddagger}$ Institute of Low Temperature and Structure Research, Polish Academy of Sciences, Okólna 2, 50-422 Wrocław, Poland

\# Department of Chemistry and Chemical Biology, Rutgers University, Piscataway, NJ 08854, USA

"Department of Chemistry, Princeton University, Princeton, New Jersey 08544, United States

Table S1 Unit cell parameters and atomic coordinates for the relaxed unit cell of PdGa.

\begin{tabular}{|l|l|l|l|}
\hline \multicolumn{2}{|l|}{ Space group } & \multicolumn{2}{l|}{ I 4/m c m (no. 140) } \\
\hline \multicolumn{2}{|l|}{ Unit cell parameters $(\AA)$} & \multicolumn{2}{l|}{$\begin{array}{l}a=b=6.38772 \\
c=9.92112\end{array}$} \\
\hline & $x$ & $y$ & $z$ \\
\hline Pd & $o$ & $o$ & $1 / 4$ \\
\hline Ga1 & $o$ & $o$ & 0 \\
\hline Ga2 & 0.35415 & 0.85415 & 0.63928 \\
\hline
\end{tabular}

Table S2 Unit cell parameters obtained from a LeBail fit to the powder x-ray diffraction pattern collected on a few, finely ground single crystals. The reliability factors given are conventional Rietveld (background corrected) R-factors calculated only for points with Bragg contributions.

\begin{tabular}{|l|l|}
\hline Space group & $I 4 / m$ c m (no. 140) \\
\hline Unit cell parameters $(\AA)$ & $a=b=6.4350(1)$ \\
& $c=9.9866(2)$ \\
\hline Reliability factors: & $R_{p}=12.0 \%$ \\
& $R_{w p}=15.6 \%$ \\
& $R_{\exp }=11.45 \%$ \\
& $\chi^{2}=1.87$ \\
\hline
\end{tabular}

Page S1 